Acta Chir Belg, 2008, 108, 66

\title{
Milestones in Pancreas Transplantation in Belgium
}

\author{
A. De Roover, J.-P. Squifflet \\ Department of Transplantation Surgery, C.H.U. Liège.
}

25 years of Pancreas Transplantation anniversary meeting, Palais des Congrès, Liège, Belgium (November 14-15, 2007)

Key word. Pancreas transplantation.

Currently, the burden and opportunity for successful pancreas transplantation is regularly based on the experience of the transplant team and mostly surgeons who pioneered that field.

Insulin independence in a type 1 diabetic patient was first achieved on December 17, 1966 when William Kelly and Richard Lillehei transplanted a duct - ligated segmental pancreas graft simultaneously with a kidney from a cadaver donor into a 28-year-old uremic woman at the University of Minnesota (1). Today, 40 years later, more than 25.000 transplants have been performed worldwide (2). According to the International Pancreas Transplant Registry (IPTR), more than $90 \%$ of the pancreatic grafts are still functioning after 1 year, for all three categories of transplants i.e. simultaneous pancreas and kidney (SPK), pancreas after kidney (PAK) and pancreas transplantation alone (PTA).

Despite the fact that heart beating donation was first used in Belgium in 1963 and opened the field of multiple organ procurement in deceased donors and simultaneous transplantation in recipients (3), one had to wait until 1982 to have the first double transplantation in Belgium, either heart and lungs transplantation (4) or SPK (3).

Since 1982, all seven Belgian transplantation centers started a pancreas program, took different attitudes and followed specific protocols according to different surgical and medical backgrounds. The influence of Belgian and International Pioneering Leaders was obvious.

During the 25 years of Pancreas Transplantation anniversary meeting, which was hold at the Palais des
Congrès, in Liège, Belgium (November 14-15, 2007), those leaders highlighted their experience which leaded to current, outstanding results in pancreas transplantation. Surgical techniques, contemporary immunosuppressive regimens, and the latest results of beta cell replacement therapy were the focus of that hallmark symposium, with special attention on future perspectives. From the past to the future !

\section{References}

1. Kelly W. D., Lillehei R. C., Merkel F. K., Idezuki Y., Goetz F. C. Allotransplantation of the pancreas and duodenum along with the kidney in diabetic nephropathy. Surgery, 1967, 61 : 827-835.

2. Gruessner A. C., Sutherland D. E. R. Pancreas transplant outcomes for United States (US) and non-US cases as reported to the United Network for organ Sharing (UNOS) and the International Pancreas Transplant Registry (IPTR) as of October 2002. In : Cecka J. M., Terasaki P. I. (eds.). Clinical Transplant. UCLA Immunogenetics Center, Los Angeles, Ca, 2002 : 41-77.

3. SQuifflet J. P. The History of Transplantation at the Catholic University of Louvain, Belgium. 1963-2003. Acta Chir Belg, 2003, $103: 10-20$.

4. De Pauw L. Organ Transplantation Pioneers at the "Université de Bruxelles". Acta Chir Belg, 2003, 103 : 25-27.

Dr. A. De Roover, M.D.

Prof. J.-P. Squifflet, M.D., Ph.D.

University of Liege

Department of Abdominal Surgery and

Transplantation (Prof. Michel Meurisse)

CHU Sart Tilman, B 35

B-4000 Liege, Belgium

Tel. : $\quad+3243667243$

Fax : + 3243667069

E-mail : Jean-Paul.Squifflet@chir-transplantation.be 